\title{
Preconditioning protects the heart in a prolonged uremic condition
}

\author{
Gabriella F. Kocsis, ${ }^{1 *}$ Márta Sárközy, ${ }^{1 *}$ Péter Bencsik, ${ }^{2}$ Márton Pipicz, ${ }^{1}$ Zoltán V. Varga, ${ }^{1}$ János Pálóczi, ${ }^{1}$ \\ Csaba Csonka, ${ }^{1,2}$ Péter Ferdinandy, ${ }^{2,3}$ and Tamás Csont ${ }^{1,2}$ \\ ${ }^{1}$ Cardiovascular Research Group, Department of Biochemistry, Faculty of Medicine, University of Szeged, Szeged, Hungary; \\ ${ }^{2}$ Pharmahungary Group, Szeged, Hungary; and ${ }^{3}$ Department of Pharmacology and Pharmacotherapy, Semmelweis University, \\ Budapest, Hungary
}

Submitted 15 May 2012; accepted in final form 6 September 2012

\begin{abstract}
Kocsis GF, Sárközy M, Bencsik P, Pipicz M, Varga ZV, Pálóczi J, Csonka C, Ferdinandy P, Csont T. Preconditioning protects the heart in a prolonged uremic condition. Am J Physiol Heart Circ Physiol 303: H1229-H1236, 2012. First published September 14, 2012; doi:10.1152/ajpheart.00379.2012.—Metabolic diseases such as hyperlipidemia and diabetes attenuate the cardioprotective effect of ischemic preconditioning. In the present study, we examined whether another metabolic disease, prolonged uremia, affects ischemia/reperfusion injury and cardioprotection by ischemic preconditioning. Uremia was induced by partial nephrectomy in male Wistar rats. The development of uremia was verified 29 wk after surgery. Transthoracic echocardiography was performed to monitor cardiac function. At week 30, hearts of nephrectomized and sham-operated rats were isolated and subjected to a 30-min coronary occlusion followed by 120 min reperfusion with or without preceding preconditioning induced by three intermittent cycles of brief ischemia and reperfusion. In nephrectomized rats, plasma uric acid, carbamide, and creatinine as well as urine protein levels were increased as compared with shamoperated controls. Systolic anterior and septal wall thicknesses were increased in nephrectomized rats, suggesting the development of a minimal cardiac hypertrophy. Ejection fraction was decreased and isovolumic relaxation time was shortened in nephrectomized rats demonstrating a mild systolic and diastolic dysfunction. Infarct size was not affected significantly by nephrectomy itself. Ischemic preconditioning significantly decreased infarct size from $24.8 \pm 5.2 \%$ to $6.6 \pm 1.3 \%$ in the sham-operated group and also in the uremic group from $35.4 \pm 9.5 \%$ to $11.9 \pm 3.1 \%$ of the area at risk. Plasma ANG II and nitrotyrosine were significantly increased in the uremic rats. We conclude that although prolonged experimental uremia leads to severe metabolic changes and the development of a mild myocardial dysfunction, the cardioprotective effect of ischemic preconditioning is still preserved.
\end{abstract}

chronic renal failure; myocardium; ischemic preconditioning; infarct size; myocardial function

ISCHEMIC PRECONDITIONING IS a well-characterized endogenous adaptive response of the myocardium in which brief cycles of ischemia markedly enhance the ability of the heart to withstand a subsequent ischemic injury (15). Although preconditioning confers remarkable cardioprotection in a variety of species $(15$, $44)$, including humans $(21,49,55)$, we and others have shown that its effectiveness is attenuated by some risk factors and comorbidities such as metabolic diseases including hyperlipidemia $(14-16)$ and diabetes $(35,54)$ both in animal models and humans (15).

Increasing prevalence of hyperlipidemia and diabetes in the aging population results in a dramatic rise in the prevalence of

\footnotetext{
* G. F. Kocsis and M. Sárközy contributed equally to this article.

Address for reprint requests and other correspondence: T. Csont, Cardiovascular Research Group, Dept. of Biochemistry, Univ. of Szeged, Dóm tér 9, Szeged, H-6720 Hungary (e-mail: csont.tamas@med.u-szeged.hu).
}

chronic kidney disease characterized by severe metabolic changes generally termed as uremia. The majority of patients suffering from uremia remain unaware of their condition for several years until reaching late stages of chronic kidney disease $(5,37)$. Uremia and especially end-stage renal failure have been shown to increase the risk of cardiovascular morbidity and mortality $(18,24)$. The prevalence of coronary artery disease at the start of dialysis is $\sim 40 \%$ (53). In fact, cardiovascular disease is the main cause of death in patients with chronic renal failure $(18,50)$. The incidence of myocardial infarction is high in dialysis patients, and the outcome after myocardial infarction is poor (2). Left ventricular dysfunction is notable in a significant number of patients on chronic dialysis, especially after acute myocardial infarction (2, 19, 26). One may speculate that the metabolic changes seen in uremia may interfere with endogenous cardioprotective mechanisms as seen with other metabolic diseases. However, there are limited data on the possible interaction of uremia with endogenous adaptive cardioprotective mechanisms including pre- and postconditioning.

A preliminary study from our research group has previously demonstrated for the first time in the literature that the infarct size limiting effect of ischemic postconditioning is still preserved in experimental chronic renal failure $10 \mathrm{wk}$ after subtotal nephrectomy (32). Byrne et al. (4) has recently reported that ischemic preconditioning, remote ischemic conditioning, and ischemic postconditioning are still cardioprotective after 4 wk of subtotal nephrectomy. These studies may suggest that the uremic heart can still be protected by conditioning techniques. However, an experimental model of $4 \mathrm{wk}$ of uremia may not properly reflect the clinical situation, since uremia remains unexplored until late stages of kidney disease in a significant number of patients (8). Thus the effect of prolonged experimental uremia on the cardioprotective effect elicited by endogenous cardioprotective mechanisms is still not known (8); however, the duration of the uremic condition may be an important determinant of the efficacy of ischemic pre- and postconditioning (8). Indeed, it has been shown earlier that $2 \mathrm{wk}(54)$ of experimental diabetes protected the myocardium against ischemia/reperfusion injury; however, 4 or $8 \mathrm{wk}$ of experimental diabetes abolished the protection by ischemic preconditioning $(15,54)$.

Therefore, in the present study we examined the influence of prolonged uremia ( $30 \mathrm{wk}$ ) on the severity of ischemia/reperfusion injury and the infarct size limiting effect of ischemic preconditioning.

\section{MATERIALS AND METHODS}

This investigation conforms to the National Institutes of Health Guide for the Care and Use of Laboratory Animals (NIH Publication 
No. 85-23, Revised 1996) and was approved by the Animal Research Ethics Committee of the University of Szeged.

Adult male Wistar rats were used in the study. Animals were housed in pairs in individually ventilated cages (Sealsafe IVC system, Italy) and were maintained in a temperature-controlled room with a 12-h:12-h light/dark cycles throughout the study. Standard rat chow and tap water were supplied ad libitum. Drinking water contained 1 $\mathrm{mg} / 100 \mathrm{~g}$ body wt iron (II) sulfate to attenuate the development of severe anemia.

Experimental setup. Experimental prolonged uremia was induced by partial (5/6) nephrectomy. Animals underwent sham operation or partial nephrectomy in two phases (Fig. 1) (42). There was no difference in mortality between sham-operated and partially nephrectomized groups. At week 29, cardiac function was assessed by transthoracic echocardiographic examination. At week 29, a group of animals were placed for $24 \mathrm{~h}$ in metabolic cages to estimate creatinine clearance and to measure urine creatinine and protein levels. At week 30 , rats were anesthetized, and hearts were isolated and perfused ex vivo by oxygenated Krebs-Henseleit solution according to Langendorff as described previously (31). Immediately after excision of the heart, blood was collected from the thoracic cavity to measure plasma uric acid, carbamide, and creatinine levels to verify the development of uremia. Some plasma was used for the determination of ANG II as an indirect marker of hypertension and hypertrophy (20, $27,28,43,58)$ and nitrotyrosine as a marker of systemic nitrosative stress (7). To assess the cardioprotective effect of ischemic preconditioning in the hearts of uremic and sham-operated animals, the perfused hearts were subjected to ischemia/reperfusion with or without preconditioning protocol. At the end of the appropriate perfusion protocol, the coronary artery was reoccluded and the area at risk and the infarcted area were delineated using an Evans blue/triphenyltetrazolium chloride double staining method (6).

Partial nephrectomy. Anesthesia was induced by intraperitoneal injection of pentobarbital sodium (Euthasol; $50 \mathrm{mg} / \mathrm{kg}$; Produlab Pharma b.v., Raamsdonksveer, The Netherlands). After depilation and a ventral midline incision in the abdominal wall, the intestines were retracted laterally to expose the animal's left kidney. The kidney was freed from the perirenal adipose tissue and renal capsule. Two pieces of sutures (5-0 Mersilk; Ethicon, Sommerville, NJ) were placed around both poles of the kidney approximately at their $1 / 3$ position. The sutures were gently ligated around the kidney. The 1/3 kidney on both ends was excised right beyond the ligatures. The abdominal incision was closed with running sutures. One week after the first operation, animals were anesthetized and prepared as described above (42). The right kidney was freed from the surrounding adipose tissue and renal capsule, and then it was pulled out of the incision gently. The adrenal gland, which is attached loosely to the anterior pole of the kidney, was gently freed and was placed back into the abdominal cavity. The renal blood vessels and the ureter were ligated, and the right kidney was removed (29). The incision was then closed with running sutures, and povidone iodide was applied on the surface of the skin. After operation, animals were placed on a warm heating pad until they become conscious again. As a post-operative medication, $0.3 \mathrm{mg} / \mathrm{kg}$ nalbuphine hydrochloride (Nalbuphine $10 \mathrm{mg} / \mathrm{ml}$; TEVA, Debrecen, Hungary) was administered subcutaneously. Antibiotics (Enroxil, $75 \mathrm{mg}$; Krka, Slovenia) and analgesics (10 mg/l of nalbuphine hydrochloride, Nalbuphine; TEVA) were administered in tap water for 2 days after both surgeries.

Transthoracic echocardiography. Cardiac function was assessed by transthoracic echocardiographic examination $29 \mathrm{wk}$ after the second surgery. Echocardiography was performed as described previously (39). The rats were anesthetized with pentobarbital sodium (Euthasol, $40 \mathrm{mg} / \mathrm{kg}$ body wt ip), the chest was shaved, and the animal was placed in supine position onto a heating pad. Two-dimensional, M-mode and Doppler echocardiographic examinations were performed in accordance with the criteria of the American Society of Echocardiography with a Vivid 7 Dimension ultrasound system (General Electric Medical Systems) using a phased array $5.5-12 \mathrm{MHz}$ transducer (10S probe). Data of three consecutive heart cycles were analyzed (EchoPac Dimension software; General Electric Medical Systems) by an experienced investigator in a blinded manner. The mean values of three measurements were calculated and used for

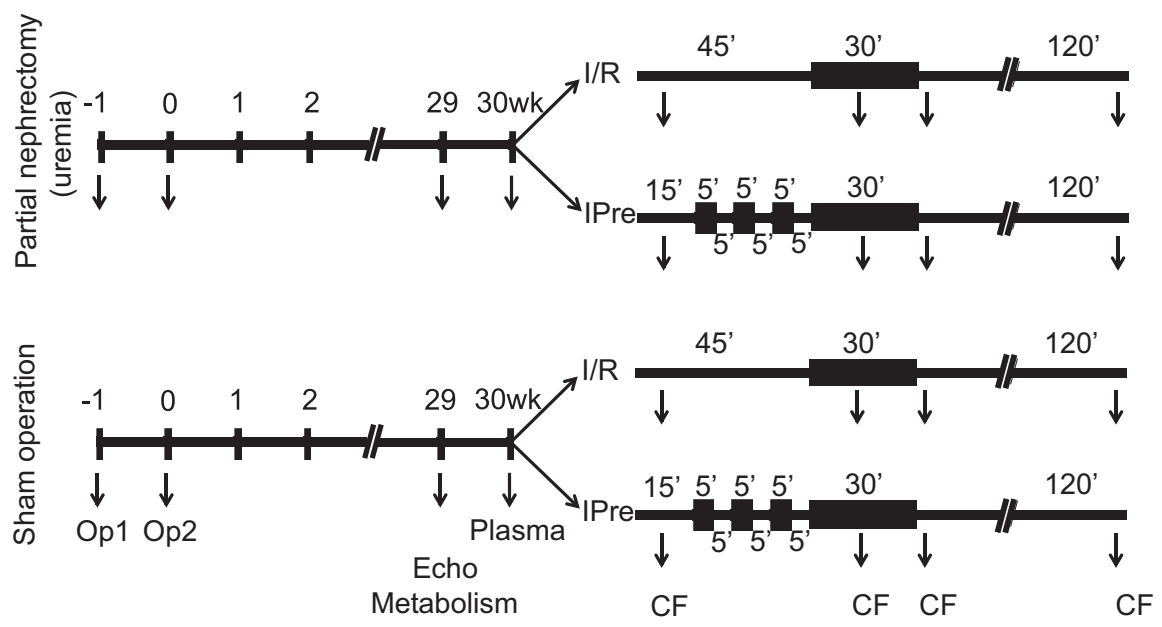

Fig. 1. Wistar rats underwent sham operation or partial nephrectomy in 2 phases. First, $2 / 3$ of the left kidney was ligated and excised (Op1). One week later, the right kidney was removed (Op2). Corresponding time-matched sham operations were performed in the sham group. At week 29, cardiac function was assessed by transthoracic echocardiographic examination (Echo). In this week the animals (12-12 in uremia and sham groups) were placed for $24 \mathrm{~h}$ in a metabolic cage (Metabolism) to determine urine creatinine and protein levels. At week 30, rats were anesthetized and blood was collected from thoracic cavity to measure plasma carbamide and creatinine levels (Plasma). Hearts were then isolated and perfused according to Langendorff. After 15 min of aerobic perfusion, hearts were subjected to either preconditioning induced by 3 intermittent periods of 5 -min ischemia/reperfusion (I/R) cycles or a time-matched (30 min) aerobic perfusion, both followed by a 30-min coronary occlusion and 2-h reperfusion ( $n=6-9$ in each group). Coronary flow (CF) was measured 10 min after the start of perfusion, in the 15th min of ischemia, in the first $5 \mathrm{~min}$ of reperfusion and at the end of the reperfusion. IPre, ischemic preconditioning (IPre). 
statistical evaluation. Systolic and diastolic wall thickness parameters were obtained from parasternal short-axis view at the level of the papillary muscles and long-axis view at the level of the mitral valve. The left ventricle diameters were measured by means of M-mode echocardiography from long-axis and short-axis views between the endocardial borders. Functional parameters including left ventricular end-diastolic volume, left ventricular end-systolic volume, and ejection fraction were calculated on four-chamber view images. Diastolic function was assessed using pulse-wave Doppler across the mitral valve from the apical four-chamber view. Early (E) and atrial (A) flow velocity as well as mitral valve deceleration time and isovolumic relaxation time provide an indication of diastolic function.

Urine creatinine and total protein levels. At week 29, the animals were placed in a metabolic cage (Techniplast, Italy) for $24 \mathrm{~h}$ to collect urine for the measurement of urine creatinine and protein levels to verify the development of advanced uremia.

Urine creatinine and urine protein levels were measured by standard laboratory methods as described previously by others $(11,40)$.

Plasma carbamide and creatinine levels. Blood was collected from the thoracic cavity after isolation of the heart to measure plasma carbamide and creatinine levels to verify the development of chronic uremia at week 30. Plasma carbamide and creatinine levels were measured in triplicate, using commercially available colorimetric assay kits (Diagnosticum, Budapest, Hungary) applying enzymatic determinations adapted to 96-well plates.

Creatinine clearance. Creatinine clearance, an indicator of renal function, was calculated according to the standard formula (urine creatinine concentration $[\mu \mathrm{M}] \times$ urine volume for $24 \mathrm{~h}[\mathrm{ml}]) /($ plasma creatinine concentration $[\mu \mathrm{M}] \times 24 \times 60$ min).

Hematocrit and hemoglobin level. Hematocrit and hemoglobin were measured from whole blood by means of a blood gas analyzer (Radiometer ABL 77; Radiometer Medical, Bronshoj, Denmark) at week 30 to verify the development of renal anemia.

Ex vivo cardiac perfusions and infarct size determination. At week 30 , rats were anesthetized and hearts were isolated and perfused at $37^{\circ} \mathrm{C}$ according to Langendorff with oxygenated Krebs-Henseleit buffer as previously described $(14,31)$. Hearts from the shamoperated and the uremic groups were further subdivided into two subgroups $(n=6-9)$ and subjected to either a nonconditioning or a preconditioning perfusion protocol, respectively (Fig. 1). Nonconditioned hearts were subjected to time-matched aerobic perfusion followed by test ischemia-reperfusion induced by a 30-min occlusion of the left descending coronary artery. Preconditioned hearts were subjected to three intermittent periods of 5-min ischemia/reperfusion followed by test ischemia/reperfusion. A 3-0 silk suture was placed around the origin of the left descending coronary artery and passed through a plastic tube to form a snare. After stabilization of the heart, coronary occlusion was induced by pulling the ends of the suture taut and clamping the snare onto the epicardial surface. Reperfusion was achieved by releasing the snare as previously described $(9,31)$. Heart rate and coronary flow were monitored throughout the perfusion protocol (Fig. 1). At the end of the 2-h reperfusion protocol, the coronary artery was reoccluded and $5 \mathrm{ml}$ of $0.1 \%$ Evans blue dye (Merk, Germany) was injected into the aorta to delineate the area-atrisk zone. Stained hearts were weighed, frozen, sliced, and incubated at $37^{\circ} \mathrm{C}$ in $1 \%$ triphenyl-tetrazolium chloride (Sigma Aldrich, Germany) to delineate infarcted tissue. Slices were then fixed and quantified by planimetry using Infarctsize 2.5 software (Pharmahungary, Szeged, Hungary) (31). Infarct size was expressed as a percentage of the area-at-risk zone (6). The area at risk was calculated as a percentage of total ventricular area (6).

Plasma ANG II level. Plasma ANG II level was determined as a marker of hypertension and left ventricular hypertrophy. The level of ANG II in blood plasma of uremic and sham-operated rats was determined with enzyme linked immunosorbent assay (ELISA) kits recognizing rat peptides (Phoenix Pharmaceuticals) in accordance with the manufacturer's instructions.

Plasma 3-nitrotyrosine level. Plasma 3-nitrotyrosine level was determined as a marker of systemic nitrosative stress. Free 3-nitrotyrosine level was measured by ELISA (Cayman Chemical) as described earlier (7) from sham and uremic plasma samples taken at week 30. Briefly, supernatants of deproteinized plasma samples were concentrated and then incubated overnight with anti-nitrotyrosine rabbit IgG specific to free 3-nitrotyrosine and nitrotyrosine acetylcholinesterase tracer in precoated (mouse anti-rabbit IgG) microplates followed by development with Ellman's reagent. Free nitrotyrosine content was expressed as nanograms per milliliter plasma.
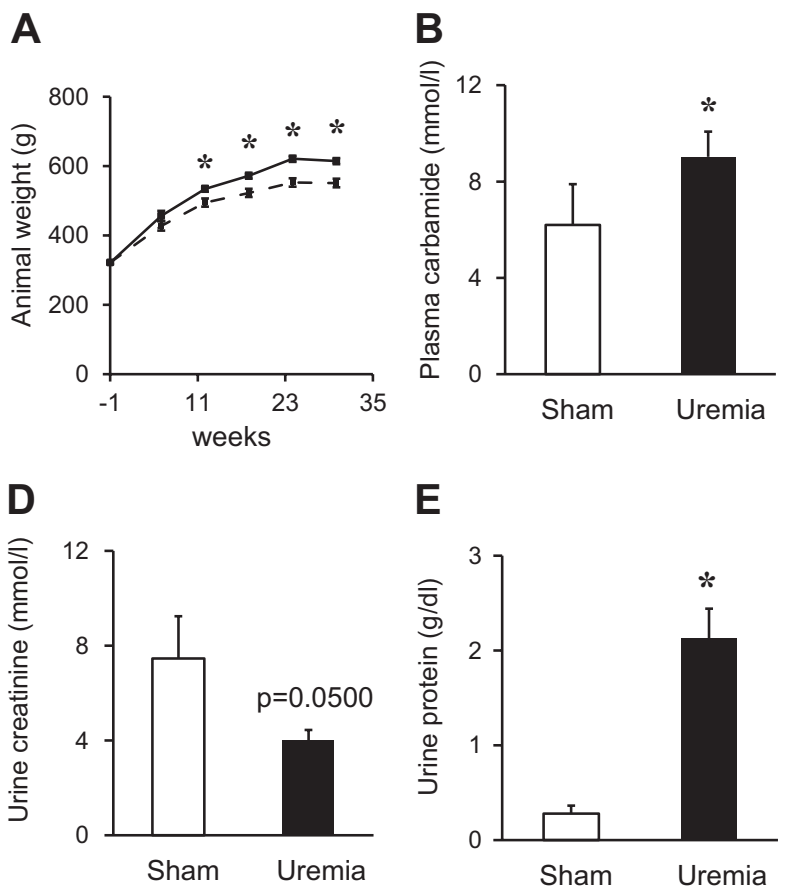

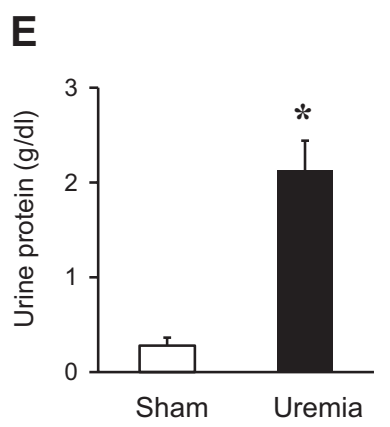

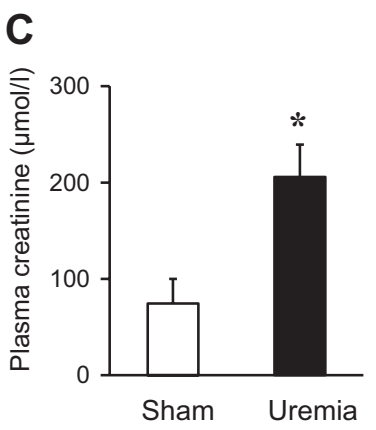

$\mathbf{F}$

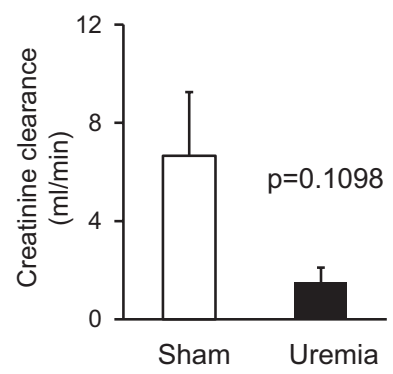

Fig. 2. Animal weight $(A)$ shown in every $6 \mathrm{wk}$. Solid line, Sham; dashed line, uremia. Plasma carbamide $(B ; n=14$ in both groups) and creatinine $(C, n=12-15)$, urine creatinine $(D$; $n=12$ in each groups) and protein concentrations $(E ; n=10-12)$ and creatinine clearance $(F ; n=9$ to 10$)$ in both sham-operated and uremic rats are shown. Values are means \pm SE. $* P<0.05$. 
Plasma uric acid level. Plasma uric acid level was measured to further characterize our uremic model. Plasma uric acid level was measured in duplicate, using a commercially available colorimetric assay kit (Diagnosticum, Budapest, Hungary) according to the manufacturer's instructions.

Statistical analysis. All values are presented as means \pm SE. Two-way ANOVA was used to determine the effect of uremia or preconditioning on infarct size, area at risk, and coronary flow. To analyze the effect of preconditioning on infarct size within shamoperated as well as uremic groups, an unpaired $t$-test was then applied. All other parameters were analyzed by unpaired $t$-tests comparing data in the uremic groups with sham-operated controls. $P<0.05$ was accepted as a statistically significant difference.

\section{RESULTS}

Characterization of prolonged uremia. To verify the development of long-term uremia induced by partial nephrectomy, body weight was monitored during the experiment and concentrations of several plasma and urine metabolites were measured at week 29. Partially nephrectomized rats showed significantly lower body weights starting from week 7 showing uremic cachexia (Fig. 2A). Plasma carbamide and creatinine levels were markedly increased in partially nephrectomized rats representing the uremic state of these animals (Fig. 2, $B$ and $C$ ). Plasma glucose levels were similar in both the shamoperated and the partially nephrectomized groups $(5.7 \pm 0.1$ vs. $5.0 \pm 0.2 ; n=13-16$; not significant). Urine protein concentration was significantly increased in the partially nephrectomized rats as compared with sham-operated controls (Fig. 2E) showing an impaired renal function. Moreover, urine creatinine level and creatinine clearance showed a marked but statistically not significant decrease at the level of $P<0.05$ in partially nephrectomized rats (Fig. 2, $D$ and $F$ ). Hematocrit and hemoglobin levels were significantly decreased in uremic animals $(44.7 \pm 2.2 \%$ and $15.0 \pm 0.7 \mathrm{~g} / \mathrm{dL}$, respectively; $n=6$ ) when compared with sham-operated rats $(54.2 \pm 1.0 \%$ vs. and $17.7 \pm 0.3 \mathrm{~g} / \mathrm{dL}$ respectively; $n=10$ ) showing renal anemia.

Effect of prolonged uremia on myocardial morphology and function. Transthoracic echocardiography was performed at week 29 to investigate whether the development of prolonged uremia leads to alteration of myocardial morphology and function. Left

Table 1. Effects of uremia on various in vivo left ventricular morphological and functional parameters measured by transthoracic echocardiography

\begin{tabular}{|c|c|c|c|c|}
\hline \multicolumn{5}{|c|}{ Echocardiography } \\
\hline \multicolumn{5}{|l|}{ Morphology } \\
\hline \multicolumn{5}{|l|}{ Wall thickness, mm } \\
\hline \multicolumn{5}{|l|}{ Anterior } \\
\hline Systolic & short axis/MM & $3.31 \pm 0.05$ & $3.59 \pm 0.11 *$ & 0.032 \\
\hline Diastolic & short axis/MM & $1.87 \pm 0.07$ & $1.97 \pm 0.09$ & 0.371 \\
\hline Diastolic & short axis/MM & $2.14 \pm 0.40$ & $1.98 \pm 0.08$ & 0.270 \\
\hline \multicolumn{5}{|l|}{ Posterior } \\
\hline Systolic & long axis/MM & $3.77 \pm 0.11$ & $3.81 \pm 0.11$ & 0.781 \\
\hline Diastolic & long axis/MM & $2.18 \pm 0.07$ & $2.30 \pm 0.08$ & 0.287 \\
\hline \multicolumn{5}{|l|}{ Septal } \\
\hline Systolic & long axis/MM & $2.70 \pm 0.12$ & $3.04 \pm 0.13^{*}$ & 0.046 \\
\hline Diastolic & long axis/MM & $2.25 \pm 0.10$ & $2.26 \pm 0.08$ & 0.961 \\
\hline \multicolumn{5}{|l|}{ Systolic function } \\
\hline$n$ & & 14 & 16 & \\
\hline Ejection fraction, $\%$ & four chamber/2D & $54.9 \pm 1.7$ & $48.9 \pm 1.4^{*}$ & 0.012 \\
\hline Stroke volume, $\mu l$ & four chamber/2D & $252.2 \pm 13.8$ & $222.9 \pm 10.1$ & 0.093 \\
\hline \multicolumn{5}{|l|}{ Left ventricular volume, $\mu \mathrm{l}$} \\
\hline End systolic & four chamber/2D & $219.3 \pm 23.1$ & $240.0 \pm 18.7$ & 0.487 \\
\hline End diastolic & four chamber/2D & $477.0 \pm 36.1$ & $461.7 \pm 27.3$ & 0.736 \\
\hline Heart rate, beats/min & four chamber/2D & $391.1 \pm 6.9$ & $396.1 \pm 4.9$ & 0.565 \\
\hline \multicolumn{5}{|l|}{ Diastolic function - Doppler imaging } \\
\hline n & & 13 & 14 & \\
\hline E-wave, $\mathrm{m} / \mathrm{s}$ & four chamber/PW & $0.82 \pm 0.03$ & $0.85 \pm 0.03$ & 0.664 \\
\hline A-wave, $\mathrm{m} / \mathrm{s}$ & four chamber/PW & $0.50 \pm 0.03$ & $0.51 \pm 0.02$ & 0.889 \\
\hline E-to-A ratio & four chamber/PW & $1.69 \pm 0.07$ & $1.72 \pm 0.09$ & 0.830 \\
\hline Deceleration time, $\mathrm{ms}$ & four chamber/PW & $33.98 \pm 1.95$ & $34.39 \pm 1.75$ & 0.885 \\
\hline
\end{tabular}

Values are means $\pm \mathrm{SE} ; n=13-16$. Transthoracic echocardiographic measurements were performed $29 \mathrm{wk}$ after sham operation or partial nephrectomy. $* P<0.05$ vs. sham, unpaired $t$-test. MM, M (motion) mode; 2D, 2-dimensional; PW, pulse wave; E-wave, early ventricular filling velocity; A-wave, late or atrial ventricular filling velocity. 
Table 2. Effects of uremia on ex vivo coronary flow data

\begin{tabular}{|c|c|c|c|}
\hline \multicolumn{4}{|c|}{ Coronary flow } \\
\hline Time points of the measurements & Sham & Uremia & $P$ Value \\
\hline \multicolumn{4}{|c|}{ During nonconditioning perfusion protocol } \\
\hline$n$ & 8 & 9 & \\
\hline Baseline, $\mathrm{ml} / \mathrm{min}$ & $16.9 \pm 1.3$ & $13.1 \pm 1.1 *$ & 0.044 \\
\hline $15^{\text {th }} \mathrm{min}$ of ischemia, $\mathrm{ml} / \mathrm{min}$ & $8.6 \pm 0.9$ & $7.4 \pm 0.5$ & 0.260 \\
\hline First $5 \mathrm{~min}$ of reperfusion, $\mathrm{ml} / \mathrm{min}$ & $19.0 \pm 1.3$ & $16.9 \pm 1.6$ & 0.367 \\
\hline End of reperfusion, $\mathrm{ml} / \mathrm{min}$ & $13.0 \pm 0.7$ & $9.4 \pm 1.1 *$ & 0.023 \\
\hline
\end{tabular}

During preconditioning perfusion protocol

\begin{tabular}{lrrr}
$n$ & \multicolumn{1}{c}{6} & 7 & \\
Baseline, $\mathrm{ml} / \mathrm{min}$ & $17.5 \pm 1.1$ & $13.0 \pm 0.6^{*}$ & 0.007 \\
$15^{\text {th }} \mathrm{min}$ of ischemia, $\mathrm{ml} / \mathrm{min}$ & $8.6 \pm 0.7$ & $6.4 \pm 0.7$ & 0.071 \\
First $5 \mathrm{~min}$ of reperfusion, $\mathrm{ml} / \mathrm{min}$ & $22.2 \pm 1.1$ & $15.5 \pm 1.7^{*}$ & 0.016 \\
End of reperfusion, $\mathrm{ml} / \mathrm{min}$ & $14.1 \pm 0.9$ & $8.4 \pm 0.8^{*}$ & 0.003
\end{tabular}

Values are means $\pm \mathrm{SE} ; n=6-9$. Studies were performed on ex vivo Langendorff heart perfusion system $30 \mathrm{wk}$ after sham operation or partial nephrectomy, $* P<0.05$ vs. sham, unpaired $t$-test.

ventricular systolic anterior and septal wall thicknesses were increased in uremic rats as compared with sham-operated controls (Table 1). However, there was no difference in diastolic anterior and septal wall thickness between the uremic and shamoperated group. In addition, left ventricular lateral and posterior wall thickness both in systole and diastole were similar in the uremic and the sham-operated groups (Table 1). Uremic animals demonstrated a mild reduction both in left ventricular systolic and diastolic function at week 29. Ejection fraction was significantly reduced in the uremic group as compared with the sham-operated control group (Table 1). Stroke volume showed a tendency of decrease in uremic animals as compared with sham-operated controls (Table 1). Heart rate and left ventricular end-systolic and end-diastolic volumes were similar in both uremic and sham-operated groups (Table 1). Isovolumic relaxation time was decreased in uremic rats as compared with sham-operated controls (Table 1). Other diastolic functional parameters including early and late ventricular filling velocity, E/A ratio, deceleration time, and maximal and mean left ventricular gradient were not changed in the uremic group as compared with sham-operated controls (Table 1).

Effect of prolonged uremia on ex vivo morphological and functional parameters. Coronary flow and morphological parameters including heart weight, left kidney weight, and tibia length were measured at week 30 to investigate whether advanced uremia influences ex vivo functional and morphological parameters of the heart. Coronary flow was significantly reduced in uremic groups when compared with corresponding sham-operated control groups as assessed by two-way ANOVA (Table 2). The ratio of heart weight to body weight showed a tendency of increase in uremic animals (Table 3), as a result of a significantly lower body weight in the uremic group (Fig. 2A). However, there was no difference in heart weight and heart weight-to-tibia length ratio between the uremic and the sham-operated control group (Table 3). In addition, the weight of the whole left kidney in the sham-operated group and the remaining one-third of the left kidney in the uremic group were similar, suggesting a marked renal hypertrophy in the uremic animals (Table 3).

Effect of ischemic preconditioning on infarct size. Infarct size was measured at week 30 to investigate the severity of ischemia/reperfusion injury and the cardioprotective effect of ischemic preconditioning in prolonged uremia (Fig. 3A). Preconditioning significantly decreased infarct size; however, the presence of prolonged uremia did not significantly influence the size of infarction as assessed by two-way ANOVA. Additional analysis with unpaired $t$-tests showed a significant infarct size limiting effect of preconditioning in hearts of both uremic and sham-operated rats (Fig. 4B). The area-at-risk zone was not affected significantly in any of the groups (Fig. 4A).

Effect of prolonged uremia on plasma ANG II, 3-nitrotyrosine, and uric acid levels. Partially nephrectomized rats showed significantly higher plasma ANG II level (Fig. 4A), which is a well-known marker of hypertension and left ventricular hypertrophy.

Plasma 3-nitrotyrosine level was determined as a marker of peroxynitrite and systemic nitrosative stress. Plasma 3-nitrotyrosine level was markedly increased in uremic rats as compared with sham-operated controls, representing increased systemic nitrosative stress in uremic animals (Fig. 4B).

Plasma level of uric acid, a well-known antioxidant, was significantly increased in the partially nephrectomized rats as compared with sham-operated controls (Fig. 4C) showing increased antioxidant capacity in uremic rats.

\section{DISCUSSION}

We have found here that although $30 \mathrm{wk}$ of experimental renal failure leads to severe metabolic changes and the development of myocardial dysfunction, the cardioprotective effect of ischemic preconditioning is still observed. This is the first demonstration that prolonged uremia does not interfere with the cardioprotective effect of ischemic preconditioning.

The cardioprotective effect of ischemic pre- and postconditioning is inhibited by several comorbid conditions and risk factors such as aging $(3,47,59)$, hyperlipidemia $(14-17,23$, $36,55)$, and diabetes $(35,48,54)$. However, recent evidence suggests that the cardioprotective effect of pre- and postconditioning is maintained in subacute renal failure (4 wk) (4) and short-term (10 wk) (32) model of uremia. In a preliminary study, we have demonstrated for the first time in the literature that the infarct size limiting effect of postconditioning was still present $10 \mathrm{wk}$ after subtotal nephrectomy, resulting in uremia in rats (32). Moreover, an extensive study recently published by Byrne et al. (4) has reported that ischemic preconditioning, remote ischemic conditioning, and ischemic postconditioning are still cardioprotective after 4 wk of subtotal nephrectomy. In addition, in the same study ischemic preconditioning was

Table 3. Effect of uremia on various ex vivo morphological parameters

\begin{tabular}{lccc}
\hline \hline \multicolumn{1}{c}{ Measurement } & Sham & Uremia & $P$ Value \\
\hline$n$ & 14 & 12 & \\
Heart weight, g & $2.10 \pm 0.09$ & $2.10 \pm 0.10$ & 0.980 \\
$\begin{array}{l}\text { Heart weight/body } \\
\text { weight } \times 10^{3}\end{array}$ & $3.40 \pm 0.17$ & $3.77 \pm 0.15$ & 0.126 \\
$\begin{array}{l}\text { Heart weight/tibia } \\
\text { length } \times 10^{2}\end{array}$ & $4.00 \pm 0.20$ & $4.20 \pm 0.20$ & 0.483 \\
Left kidney weight, g & $\begin{array}{c}\text { Full kidney weight } \\
1.90 \pm 0.11\end{array}$ & $\begin{array}{c}1 / 3 \text { kidney weight } \\
2.04 \pm 0.09\end{array}$ & - \\
\hline
\end{tabular}

Values are means $\pm \mathrm{SE} ; n=12-14$, unpaired $t$-test. Measurements were performed $30 \mathrm{wk}$ after sham operation or partial nephrectomy. 
Fig. 3. Area at risk (AAR; $A)$ and infarct size (IS; $B$ ) after ischemia/reperfusion (I/R) or ischemic preconditioning (IPre) in both shamoperated and uremic groups. Values are means \pm SE; $n=6-9$ in each group. Twoway ANOVA on all groups showed that preconditioning significantly decreased infarct size; however, uremia did not influence infarct size. ${ }^{*}$ Significant difference $(* P<0.05)$ by an unpaired $t$-test between $\mathrm{I} / \mathrm{R}$ and IPre groups.
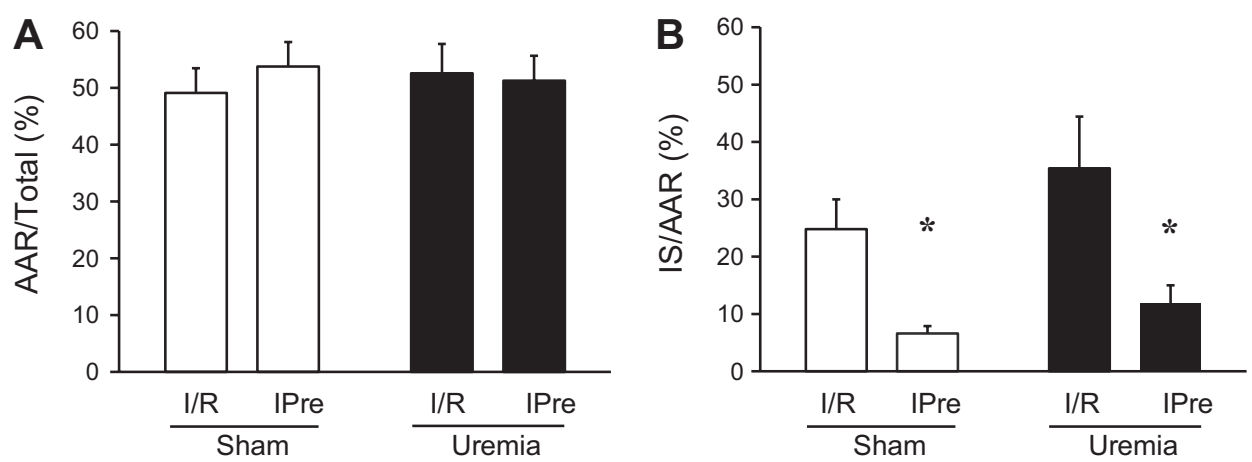

shown to limit infarct size in an adenine-enriched diet-induced model of uremia in rats (4). Although the uremic state seems to be too short and was not characterized thoroughly in Byrne's aforementioned studies $(4,8)$, they may suggest that the uremic heart can be still protected by conditioning techniques. Indeed, an experimental model of $4 \mathrm{wk}$ of uremia probably may not properly reflect the clinical situation, since uremia may remain unexplored for a long time in patients $(8,37)$. Additionally, it has been shown that $5 / 6$ partial nephrectomy followed by a postoperative duration of $3 \mathrm{wk}$ does not lead to advanced uremia in rats (10).

Therefore, in the present study we used a prolonged (30 wk) postoperative duration following partial nephrectomy to induce a more severe long-term uremic condition for investigating the cardioprotective effect of preconditioning. In this model, here we have found characteristic biochemical and pathophysiological signs of prolonged uremia, including cachexia, increased plasma uric acid, carbamide and creatinine levels, decreased hematocrit and hemoglobin, increased urine protein, and decreased creatinine concentration, as well as diminished creatinine clearance. In patients with end-stage renal failure, uremic cardiomyopathy is a common complication and reported to be a prognostic factor of cardiovascular mortality $(24,50,53)$. In the present study, we have found increased septal and anterior wall thickness in uremic animals. Additionally, plasma ANG II level, which is an indirect marker of hypertension and left ventricular hypertrophy $(20,27,28,43,58)$, was also higher in uremic rats. These results together with literature data $(1,33$, $38,41)$ suggest the development of a minimal left ventricular hypertrophy in uremic animals at week 30 in our present study. In this model, we have found here that ischemic preconditioning is still effective in prolonged uremic condition. This is a refreshingly interesting result in the light of the fact that several metabolic diseases including diabetes and hyperlipidemia in- hibit the endogenous cardioprotective mechanisms of ischemic conditioning.

The reason why the complex metabolic changes of uremia, which significantly affect several intracellular signaling pathways in the heart and lead to myocardial dysfunction, do not affect the overall efficacy of cardioprotection by ischemic preconditioning is unknown. It has been previously shown that 6- to 8-wk-long chronic renal failure leads to increased oxidative and nitrosative stress in the rat heart $(1,51,56,57)$. Here we have also shown increased nitrosative stress in a 30 -wk model of prolonged uremia. It is well known that the cardioprotective effect of ischemic preconditioning is lost in metabolic diseases associated with increased myocardial oxidative and nitrosative stress (15). Therefore, our present findings showing that the cardioprotective effect of ischemic preconditioning is surprisingly still preserved in uremic animals despite the increased systemic nitrosative stress are particularly exciting. These results suggest that even though prolonged uremia leads to some deleterious effects (e.g., mild cardiac dysfunction, tendency of increased infarct size), it likely induces some complex compensatory alterations supporting maintained cardioprotection by ischemic preconditioning. This hypothesis is further supported by our present finding showing elevated plasma levels of uric acid, a known antioxidant, in prolonged uremia. However, further studies should be carried out to determine the precise role of oxidative/nitrosative stress in the mechanism of preconditioning in uremia.

Upregulation of renal renin-angiotensin-aldosterone system was also shown in rats with partial nephrectomy in our present study similarly to findings of other research groups $(25,33$, 41). In our present study, increased plasma ANG II levels together with echocardiographic data suggest the development of a minimal left ventricular hypertrophy at week 30 in uremic animals. In this aspect our study is in line with other studies
A

Fig. 4. Plasma ANG II $(A ; n=9$ to 10$)$, nitrotyrosine $(B ; n=9$ to 10$)$, and uric acid $(C$; $n=9$ to 10 ) levels in both sham-operated and uremic rats. Values are means $\pm \mathrm{SE}$. $* P<0.05$
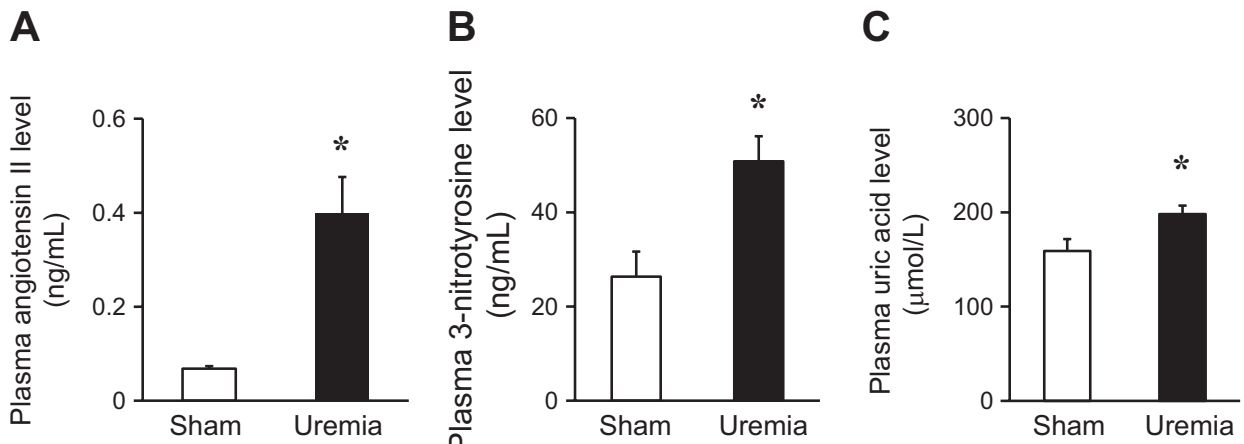
showing that ischemic preconditioning is still cardioprotective in case of left ventricular hypertrophy $(45,52)$ and hypertension $(12,13,52)$ associated with increased plasma ANG II level (15). Therefore, we believe that the presence of a minimal cardiac hypertrophy and mild left ventricular dysfunction in uremic animals might not interfere with the cardioprotective mechanism of ischemic preconditioning. However, it cannot be excluded that the cardioprotection by preconditioning may be lost with the progression of the disease and development of severe heart failure in end-stage renal failure, as it has been shown that endogenous cardioprotection is lost in severe heart failure $(22,30,34)$. In addition, renal failure seems to interact with some protein kinases $(33,38)$ suggested to be involved in the mechanism of ischemic preconditioning. Taken together, the overall net changes in uremia seem to preserve the cardioprotective effect of ischemic preconditioning; however, the exact mechanisms remain to be elucidated in further studies.

In conclusion, our present study suggests that patients suffering from long-term uremia may also benefit from cardioprotection by ischemic preconditioning. This is particularly important since acute myocardial infarction frequently occurs in patients with late stages of renal failure. Because uremic patients are regularly excluded from clinical trials, there is a need for clinical studies to investigate the cardioprotective effect of conditioning techniques in patients with chronic renal failure suffering from acute myocardial infarction.

\section{ACKNOWLEDGMENTS}

We acknowledge the excellent technical support of Judit Pipis for animal surgeries and Szilvia Török for infarct staining and biochemical assays.

\section{GRANTS}

This work was supported by grants from the National Office for Research and Technology (Baross DA-TECH-07-2008-0041; TÁMOP-4.2.1/B-09/1/ KONV-2010-0005; TÁMOP-4.2.2/B-10/1-2010-0012 and MED_FOOD) and the Hungarian Scientific Research Fund (OTKA K79167) and the Richter Gedeon Centenary Foundation and cofinanced by the European Regional Development Fund and VÁTI Hungarian Nonprofit Limited Liability Company for Regional Development and Town Planning (HURO/0901/137/2.2.2HU-RO-TRANS-MED). T. Csont holds a "János Bolyai Felowship" from the Hungarian Academy of Sciences.

\section{DISCLOSURES}

No conflicts of interest, financial or otherwise, are declared by the author(s).

\section{REFERENCES}

1. Bai Y, Sigala W, Adams GR, Vaziri ND. Effect of exercise on cardiac tissue oxidative and inflammatory mediators in chronic kidney disease. $\mathrm{Am}$ J Nephrol 29: 213-221, 2009.

2. Banerjee D, Ma JZ, Collins AJ, Herzog CA. Long-term survival of incident hemodialysis patients who are hospitalized for congestive heart failure, pulmonary edema, or fluid overload. Clin J Am Soc Nephrol 2: 1186-1190, 2007.

3. Boengler K, Konietzka I, Buechert A, Heinen Y, Garcia-Dorado D, Heusch G, Schulz R. Loss of ischemic preconditioning's cardioprotection in aged mouse hearts is associated with reduced gap junctional and mitochondrial levels of connexin 43. Am J Physiol Heart Circ Physiol 292: H1764-H1769, 2007.

4. Byrne CJ, McCafferty K, Kieswich J, Harwood S, Andrikopoulos P, Raftery M, Thiemermann C, Yaqoob MM. Ischemic conditioning protects the uremic heart in a rodent model of myocardial infarction. Circulation 125: 1256-1265, 2012.

5. Coritsidis GN, Linden E, Stern AS. The role of the primary care physician in managing early stages of chronic kidney disease. Postgrad Med 123: 177-185, 2011.
6. Csonka C, Kupai K, Kocsis GF, Novak G, Fekete V, Bencsik P, Csont T, Ferdinandy P. Measurement of myocardial infarct size in preclinical studies. J Pharmacol Toxicol Methods 61: 163-170, 2010.

7. Csont T, Csonka C, Onody A, Gorbe A, Dux L, Schulz R, Baxter GF, Ferdinandy P. Nitrate tolerance does not increase production of peroxynitrite in the heart. Am J Physiol Heart Circ Physiol 283: H69-H76, 2002.

8. Csont T, Ferdinandy P. Letter by Csont and Ferdinandy regarding article, "Ischemic conditioning protects the uremic heart in a rodent model of myocardial infarction". Circulation 126: e212, 2012.

9. Csont T, Szilvassy Z, Fulop F, Nedeianu S, Pali T, Tosaki A, Dux L, Ferdinandy P. Direct myocardial anti-ischaemic effect of GTN in both nitrate-tolerant and nontolerant rats: a cyclic GMP-independent activation of KATP. Br J Pharmacol 128: 1427-1434, 1999.

10. Dikow R, Kihm LP, Zeier M, Kapitza J, Tornig J, Amann K, Tiefenbacher C, Ritz E. Increased infarct size in uremic rats: reduced ischemia tolerance? J Am Soc Nephrol 15: 1530-1536, 2004.

11. Dunn SR, Qi Z, Bottinger EP, Breyer MD, Sharma K. Utility of endogenous creatinine clearance as a measure of renal function in mice. Kidney Int 65: 1959-1967, 2004.

12. Ebrahim Z, Yellon DM, Baxter GF. Attenuated cardioprotective response to bradykinin, but not classical ischaemic preconditioning, in DOCA-salt hypertensive left ventricular hypertrophy. Pharmacol Res 55: 42-48, 2007.

13. Ebrahim Z, Yellon DM, Baxter GF. Ischemic preconditioning is lost in aging hypertensive rat heart: independent effects of aging and longstanding hypertension. Exp Gerontol 42: 807-814, 2007.

14. Ferdinandy P, Csonka C, Csont T, Szilvassy Z, Dux L. Rapid pacinginduced preconditioning is recaptured by farnesol treatment in hearts of cholesterol-fed rats: role of polyprenyl derivatives and nitric oxide. Mol Cell Biochem 186: 27-34, 1998.

15. Ferdinandy P, Schulz R, Baxter GF. Interaction of cardiovascular risk factors with myocardial ischemia/reperfusion injury, preconditioning, and postconditioning. Pharmacol Rev 59: 418-458, 2007.

16. Ferdinandy P, Szilvassy Z, Baxter GF. Adaptation to myocardial stress in disease states: is preconditioning a healthy heart phenomenon? Trends Pharmacol Sci 19: 223-229, 1998.

17. Ferdinandy P, Szilvassy Z, Horvath LI, Csont T, Csonka C, Nagy E, Szentgyorgyi R, Nagy I, Koltai M, Dux L. Loss of pacing-induced preconditioning in rat hearts: role of nitric oxide and cholesterol-enriched diet. J Mol Cell Cardiol 29: 3321-3333, 1997.

18. Foley RN, Murray AM, Li S, Herzog CA, McBean AM, Eggers PW, Collins AJ. Chronic kidney disease and the risk for cardiovascular disease, renal replacement, and death in the United States Medicare population, 1998 to 1999. J Am Soc Nephrol 16: 489-495, 2005.

19. Foley RN, Parfrey PS, Sarnak MJ. Epidemiology of cardiovascular disease in chronic renal disease. J Am Soc Nephrol 9, Suppl 12: S16-S23, 1998.

20. Gavras I, Gavras H. Angiotensin II as a cardiovascular risk factor. J Hum Hypertens 16, Suppl 2: S2-S6, 2002.

21. Gerczuk PZ, Kloner RA. Protecting the heart from ischemia: an update on ischemic and pharmacologic conditioning. Hosp Pract (Minneap) 39: 35-43, 2011.

22. Ghosh S, Standen NB, Galinianes M. Failure to precondition pathological human myocardium. J Am Coll Cardiol 37: 711-718, 2001.

23. Giricz Z, Lalu MM, Csonka C, Bencsik P, Schulz R, Ferdinandy P. Hyperlipidemia attenuates the infarct size-limiting effect of ischemic preconditioning: role of matrix metalloproteinase-2 inhibition. J Pharmacol Exp Ther 316: 154-161, 2006.

24. Go AS, Chertow GM, Fan D, McCulloch CE, Hsu CY. Chronic kidney disease and the risks of death, cardiovascular events, and hospitalization. N Engl J Med 351: 1296-1305, 2004.

25. Goncalves AR, Fujihara CK, Mattar AL, Malheiros DM, Noronha Ide L, de Nucci G, Zatz R. Renal expression of COX-2, ANG II, and $\mathrm{AT}_{1}$ receptor in remnant kidney: strong renoprotection by therapy with losartan and a nonsteroidal anti-inflammatory. Am J Physiol Renal Physiol 286: F945-F954, 2004.

26. Herzog CA, Ma JZ, Collins AJ. Poor long-term survival after acute myocardial infarction among patients on long-term dialysis. $N$ Engl J Med 339: 799-805, 1998.

27. Israili ZH. Clinical pharmacokinetics of angiotensin II $\left(\mathrm{AT}_{1}\right)$ receptor blockers in hypertension. J Hum Hypertens 14, Suppl 1: S73-S86, 2000.

28. Jin Y, Kuznetsova T, Thijs L, Schmitz B, Liu Y, Asayama K, Brand SM, Heymans S, Brand E, Fagard R, Staessen JA. Association of left 
ventricular mass with the AGTR1 A1166C polymorphism. Am J Hypertens 25: 472-478, 2012.

29. Kasiske BL, O'Donnell MP, Garvis WJ, Keane WF. Pharmacologic treatment of hyperlipidemia reduces glomerular injury in rat 5/6 nephrectomy model of chronic renal failure. Circ Res 62: 367-374, 1988.

30. Kitakaze M, Hori M. It is time to ask what adenosine can do for cardioprotection. Heart Vessels 13: 211-228, 1998.

31. Kocsis GF, Pipis J, Fekete V, Kovacs-Simon A, Odendaal L, Molnar E, Giricz Z, Janaky T, van Rooyen J, Csont T, Ferdinandy P. Lovastatin interferes with the infarct size-limiting effect of ischemic preconditioning and postconditioning in rat hearts. Am J Physiol Heart Circ Physiol 294: H2406-H2409, 2008.

32. Kocsisne GF, Bencsik P, Fekete V, Varga ZV, Monostori P, Turi S, Ferdinandy P, Csont T. The influence of chronic renal failure on the cardioprotective effect of postconditioning in rats with partial nephrectomy (Abstract). Cardiovasc Res 87, Suppl 1: S135, 2010.

33. Koleganova N, Piecha G, Ritz E, Bekeredjian R, Schirmacher P, Schmitt CP, Gross ML. Interstitial fibrosis and microvascular disease of the heart in uremia: amelioration by a calcimimetic. Lab Invest 89: 520-530, 2009.

34. Kopecky SL, Aviles RJ, Bell MR, Lobl JK, Tipping D, Frommell G, Ramsey K, Holland AE, Midei M, Jain A, Kellett M, Gibbons RJ, AmP579 Delivery for Myocardial Infarction REduction study. A randomized, double-blinded, placebo-controlled, dose-ranging study measuring the effect of an adenosine agonist on infarct size reduction in patients undergoing primary percutaneous transluminal coronary angioplasty: the ADMIRE (AmP579 Delivery for Myocardial Infarction REduction) study. Am Heart J 146: 146-152, 2003.

35. Kristiansen SB, Lofgren B, Stottrup NB, Khatir D, Nielsen-Kudsk JE, Nielsen TT, Botker HE, Flyvbjerg A. Ischaemic preconditioning does not protect the heart in obese and lean animal models of type 2 diabetes. Diabetologia 47: 1716-1721, 2004.

36. Kupai K, Csonka C, Fekete V, Odendaal L, van Rooyen J, Marais de W, Csont T, Ferdinandy P. Cholesterol diet-induced hyperlipidemia impairs the cardioprotective effect of postconditioning: role of peroxynitrite. Am J Physiol Heart Circ Physiol 297: H1729-H1735, 2009.

37. Levey AS, Coresh J. Chronic kidney disease. Lancet 379: 165-180, 2012.

38. Li Y, Takemura G, Okada H, Miyata S, Maruyama R, Esaki M, Kanamori H, Li L, Ogino A, Ohno T, Kondo T, Nakagawa $M$, Minatoguchi S, Fujiwara T, Fujiwara H. Molecular signaling mediated by angiotensin II type $1 \mathrm{~A}$ receptor blockade leading to attenuation of renal dysfunction-associated heart failure. J Card Fail 13: 155-162, 2007.

39. Liu J, Rigel DF. Echocardiographic examination in rats and mice. Methods Mol Biol 573: 139-155, 2009.

40. Lynch KM, Sellers TS, Gossett KA. Evaluation of an automated pyrogallol red-molybdate method for the measurement of urinary protein in rats. Eur J Clin Chem Clin Biochem 34: 569-571, 1996.

41. Michea L, Villagran A, Urzua A, Kuntsmann S, Venegas P, Carrasco L, Gonzalez M, Marusic ET. Mineralocorticoid receptor antagonism attenuates cardiac hypertrophy and prevents oxidative stress in uremic rats. Hypertension 52: 295-300, 2008.

42. Morrison AB, Howard RM. The functional capacity of hypertrophied nephrons. Effect of partial nephrectomy on the clearance of inulin and PAH in the rat. $J$ Exp Med 123: 829-844, 1966.

43. Munger MA. Use of angiotensin receptor blockers in cardiovascular protection: current evidence and future directions. $P$ T 36: 22-40, 2011.

44. Ovize M, Baxter GF, Di Lisa F, Ferdinandy P, Garcia-Dorado D, Hausenloy DJ, Heusch G, Vinten-Johansen J, Yellon DM, Schulz R,
Working Group of Cellular Biology of Heart of European Society of Cardiology. Postconditioning and protection from reperfusion injury: where do we stand? Position paper from the Working Group of Cellular Biology of the Heart of the European Society of Cardiology. Cardiovasc Res 87: 406-423, 2010.

45. Pantos CI, Davos CH, Carageorgiou HC, Varonos DV, Cokkinos DV. Ischaemic preconditioning protects against myocardial dysfunction caused by ischaemia in isolated hypertrophied rat hearts. Basic Res Cardiol 91: 444-449, 1996.

46. Parlakpinar H, Ozer MK, Acet A. Effects of captopril and angiotensin II receptor blockers $\left(\mathrm{AT}_{1}, \mathrm{AT}_{2}\right)$ on myocardial ischemia-reperfusion induced infarct size. Cytokine 56: 688-694, 2011.

47. Przyklenk K, Maynard M, Darling CE, Whittaker P. Aging mouse hearts are refractory to infarct size reduction with post-conditioning. $\mathrm{J} \mathrm{Am}$ Coll Cardiol 51: 1393-1398, 2008.

48. Przyklenk K, Maynard M, Greiner DL, Whittaker P. Cardioprotection with postconditioning: loss of efficacy in murine models of type- 2 and type-1 diabetes. Antioxid Redox Signal 14: 781-790, 2011.

49. Rezkalla SH, Kloner RA. Preconditioning in humans. Heart Fail Rev 12: 201-206, 2007.

50. Sarnak MJ, Levey AS, Schoolwerth AC, Coresh J, Culleton B, Hamm LL, McCullough PA, Kasiske BL, Kelepouris E, Klag MJ, Parfrey P, Pfeffer M, Raij L, Spinosa DJ, Wilson PW, American Heart Association Councils on Kidney in Cardiovascular Disease, High Blood Pressure Research, Clinical Cardiology, and Epidemiology and Prevention. Kidney disease as a risk factor for development of cardiovascular disease: a statement from the American Heart Association Councils on Kidney in Cardiovascular Disease, High Blood Pressure Research, Clinical Cardiology, and Epidemiology and Prevention. Circulation 108: 2154-2169, 2003.

51. Sindhu RK, Ehdaie A, Vaziri ND, Roberts CK. Effects of chronic renal failure on caveolin-1, guanylate cyclase and AKT protein expression. Biochim Biophys Acta 1690: 3: 231-237, 2004.

52. Speechly-Dick ME, Baxter GF, Yellon DM. Ischaemic preconditioning protects hypertrophied myocardium. Cardiovasc Res 28: 1025-1029, 1994.

53. Stack AG, Bloembergen WE. A cross-sectional study of the prevalence and clinical correlates of congestive heart failure among incident US dialysis patients. Am J Kidney Dis 38: 992-1000, 2001.

54. Tosaki A, Engelman DT, Engelman RM, Das DK. The evolution of diabetic response to ischemia/reperfusion and preconditioning in isolated working rat hearts. Cardiovasc Res 31: 526-536, 1996.

55. Ungi I, Ungi T, Ruzsa Z, Nagy E, Zimmermann Z, Csont T, Ferdinandy $\mathbf{P}$. Hypercholesterolemia attenuates the anti-ischemic effect of preconditioning during coronary angioplasty. Chest 128: 1623-1628, 2005.

56. Vaziri ND. Effect of chronic renal failure on nitric oxide metabolism. Am J Kidney Dis 38, Suppl 1: S74-S79, 2001.

57. Vaziri ND, Ni Z, Oveisi F, Liang K, Pandian R. Enhanced nitric oxide inactivation and protein nitration by reactive oxygen species in renal insufficiency. Hypertension 39: 135-141, 2002.

58. Wright JW, Mizutani S, Harding JW. Pathways involved in the transition from hypertension to hypertrophy to heart failure. Treatment strategies. Heart Fail Rev 13: 367-375, 2008.

59. Zheng J, Chin A, Duignan I, Won KH, Hong MK, Edelberg JM. Growth factor-mediated reversal of senescent dysfunction of ischemiainduced cardioprotection. Am J Physiol Heart Circ Physiol 290: H525H530, 2006. 